OPEN ACCESS

Edited by:

Lei Wang,

Zhengzhou University, China

Reviewed by:

Alvaro Ingles Russo Garces, Institute of Cancer Research (ICR), United Kingdom Claudia Andreetta, Azienda Sanitaria Universitaria Friull

Centrale (ASU FC), Italy

*Correspondence: Ying Zhou

caddie1234@gmail.com

${ }^{\dagger}$ These authors have contributed equally to this work and share first authorship

Specialty section: This article was submitted to Gynecological Oncology, a section of the journal

Frontiers in Oncology

Received: 15 February 2021 Accepted: 17 May 2021

Published: 03 June 2021

Citation:

Chen S, Li Y, Qian L, Deng S, Liu L, Xiao $W$ and Zhou $Y$ (2021) A Review

of the Clinical Characteristics and

Novel Molecular Subtypes of Endometrioid Ovarian Cancer.

Front. Oncol. 11:668151. doi: 10.3389/fonc.2021.668151

\section{A Review of the Clinical Characteristics and Novel Molecular Subtypes of Endometrioid Ovarian Cancer}

\author{
Shuangfeng Chen ${ }^{1 \dagger}$, Yuebo $\mathrm{Li}^{2+}$, Lili Qian ${ }^{2}$, Sisi Deng ${ }^{2}$, Luwen Liu ${ }^{2}$, Weihua Xiao ${ }^{3,4}$ \\ and Ying Zhou ${ }^{1,2 *}$ \\ ${ }^{1}$ Department of Obstetrics and Gynecology, Anhui Provincial Hospital, Anhui Medical University, Hefei, China, ${ }^{2}$ Department \\ of Obstetrics and Gynecology, The First Affiliated Hospital of USTC, Division of Life Sciences and Medicine, University of \\ Science and Technology of China, Hefei, China, ${ }^{3}$ Division of Molecular Medicine, Hefei National Laboratory for Physical \\ Sciences at Microscale, The CAS Key Laboratory of Innate Immunity and Chronic Disease, School of Life Sciences, \\ University of Science and Technology of China, Hefei, China, ${ }^{4}$ Institute of Immunology, University of Science and Technology \\ of China, Hefei, China
}

Ovarian cancer is one of the most common gynecologic cancers that has the highest mortality rate. Endometrioid ovarian cancer, a distinct subtype of epithelial ovarian cancer, is associated with endometriosis and Lynch syndrome, and is often accompanied by synchronous endometrial carcinoma. In recent years, dysbiosis of the microbiota within the female reproductive tract has been suggested to be involved in the pathogenesis of endometrial cancer and ovarian cancer, with some specific pathogens exhibiting oncogenic having been found to contribute to cancer development. It has been shown that dysregulation of the microenvironment and accumulation of mutations are stimulatory factors in the progression of endometrioid ovarian carcinoma. This would be a potential therapeutic target in the future. Simultaneously, multiple studies have demonstrated the role of four molecular subtypes of endometrioid ovarian cancer, which are of particular importance in the prediction of prognosis. This literature review aims to compile the potential mechanisms of endometrioid ovarian cancer, molecular characteristics, and molecular pathological types that could potentially play a role in the prediction of prognosis, and the novel therapeutic strategies, providing some guidance for the stratified management of ovarian cancer.

Keywords: microbiota dysbiosis, molecular subtypes, treatment strategy, prognosis, molecular characteristic, endometrioid ovarian cancer

\section{INTRODUCTION}

Ovarian cancer (OC) is a global public health issue and threat to women's health. According to the Global Cancer Statistics, which includes data of 36 cancers from 185 countries, nearly 300,000 new cases of OC were diagnosed worldwide in 2018 and 184,799 women died of OC in the same year (1). These figures make OC the third most diagnosed malignancy and the leading cause of death in 
female gynecological oncology. Epithelial ovarian cancer (EOC) is the most common and lethal type of OC, further divided into the high-grade serous, low-grade serous, endometrioid, clear cell, mucinous. Up to now, the study of EOC mainly focuses on highgrade serous carcinoma. With the development of precision medicine, the therapeutic direction of carcinoma has gradually turned to targeted and stratified therapy.

Endometrioid ovarian cancer (EOVC) accounts for 10 15.8\% of EOC (2), and shows an association with endometriosis (3) and Lynch syndrome $(4,5)$. EOVC is often accompanied by synchronous endometrial carcinoma (EC) and typically diagnosed at an early stage (6). It is estimated that $84 \sim 95 \%$ of EOVC cases are of grades I and II, with grade III representing $5 \sim 16 \%$ (Table 1). More than $70 \%$ of EOVC are diagnosed at Federation International of Gynecology and Obstetrics (FIGO) III according to OC statistics in the United States in 2018 (7), and importantly, of high-grade EOVC that $65 \%$ were early stage (FIGO I/II) (8). However, some patients with EOVC still have a poor prognosis, and the proposed molecular classification may aid in providing an accurate prediction of the prognosis of patients with early-stage or low-grade EOVC, so as to better guide the clinical individualized treatment. The current pathogenesis of EOVC is also under discussion. This review introduces the origin, molecular characteristic, molecular classification, treatment and potential therapeutic strategies of EOVC and further explores factors influencing treatment choice and prognosis.

\section{EPIDEMIOLOGY AND RISK FACTORS}

EOVC and ovarian clear cell carcinoma (OCCC) make up the second and third most common types of EOC, representing $20 \sim 40 \%$. In Asia, there is a higher proportion of EOVC and OCCC and a lower proportion of serous carcinomas than other regions (9), however, the difference in distinct countries is still unclear. Multiple studies have shown that the following may increase the risk of developing EOVC: endometriosis; certain gene mutations; familial cancer syndrome (Lynch syndrome); disruption of the microbiota in the female reproductive system; age at menopause; body mass index (BMI) (10-15). Most risk factors show obvious heterogeneity in the five histologic subtypes of EOC, indicating different etiologies.

TABLE 1 | Proportions of EOVC cases with different grades and stages.

\begin{tabular}{lc}
\hline Grade/FIGO stage & Proportion(\%) \\
\hline Grade & \\
Grade1/2 & $84 \sim 95 \%$ \\
Grade3 & $5 \sim 16 \%$ \\
Stage & \\
Stage I & $50 \sim 72 \%$ \\
Stage II & $11 \sim 36 \%$ \\
Stage III & $12 \sim 14 \%$ \\
Stage IV & $1 \sim 3 \%$
\end{tabular}

\section{HYPOTHESIS OF EOVC ORIGIN}

\section{Endometriosis}

The most widely accepted hypothesis concerning endometriosis is the theory of retrograde menstruation, proposed by Sampson, who demonstrated that the shed endometrium can retrogradely enter the peritoneal cavity along the fallopian tube, and implant into the peritoneum and pelvic organs, including the ovaries, which can lay the foundations for the development of $\mathrm{OC}$ $(16,17)$.

Relevant articles have reported that approximately $25 \sim 80 \%$ of patients with EOVC and OCCC also have a diagnosis of endometriosis $(18,19)$. Patients with endometriosis have been reported to be at a $1.49,3.73$ and 2.32 times greater risk of development of OC, OCCC and EOVC respectively, compared with healthy women without endometriosis (20). In addition, approximately one third of endometrioid borderline ovarian tumors (EBOTs), are also associated with endometriosis (21). In recent years, whether or not endometriosis is a precancerous lesion of OC, in particular EOVC, has been a hot topic of concern for researchers.

A large number of studies have also found that patients with endometriosis have many gene mutations, including mutations in ARID1A, PIK3CA, KRAS, FBXW7, MLH1, ERBB2, CTNNB1, and PPP2R1A $(19,22,23)$. Following comparison of mutations present in pure endometriosis and endometriosis-related OC, several population-based studies have suggested that endometriosis is a risk factor for OC. This may be due to the gradual development of ectopic endometrial tissue that engrafts onto the ovaries, along with sufficient driver mutations $(20,24)$. Of particular note, the ARID1A gene is thought to be involved in the progression of endometriosis to carcinoma $(25,26)$. The receptor activator of nuclear factor $\kappa-B$ (RANK) signaling pathway has already been revealed to be involved in some tumor progression $(27,28)$, such as breast, bone, and lung cancers. Compared with the expression in the normal endometrium, expression of RANK is increased in patients with endometriotic lesions and EOVC (29).

Recently, an article defined "high-risk" cases as those which share the same mutations present in EOVC and endometriosis, and "low-risk" cases as those not sharing any mutations in endometriosis with the carcinoma (30). According to the literature, compared with women without endometriosis, women with endometriosis are more likely to be diagnosed with early-stage tumor, with a significantly lower level of serum CA125 before surgery, and are less likely to have lymph node metastasis or to develop platinum resistance disease (18, 31). Patients with EOVC arising from endometriosis presented at a lower average age, have a higher percentage of early-stage and lower-grade disease, and are more likely to have no residual disease after primary debulking surgery compared with those without endometriosis, which indicates better survival outcomes (32). EOVC arising from endometriosis was not statistically significant as an independent prognostic factor, therefore, endometriosis may be a possible precursor of EOVC but is not a factor that exacerbates cancer after its onset (33). Patients with endometriosis can be divided into several groups according to 
malignancy risk and there are schemes and principles used to categorize patients: ROMA (risk of ovarian malignancy algorithm), RMI (risk of malignancy index), and IOTA (International Ovarian Tumor Analysis simple rules) which are based on serum biomarkers, BMI and ultrasound findings (34).

\section{Microbial Communities in Female Reproductive Tract}

It is generally believed that the upper reproductive tracts (i.e. the uterus, fallopian tubes, and ovaries) are sterile, however, recent reports on the microbiota of the female reproductive tract haves demonstrated that bacteria are present in the uterus and ovaries $(35,36)$, however, microbial abundance is relatively low compared with the vagina and cervix. Dysregulation of the vaginal environment is a risk factor for many diseases, as upward colonization of the reproductive tract with microbiota, especially anaerobic bacteria, serves as a primary driver for inflammation, and may be involved in the development of diseases, such as gynecological cancers (37-39). Where there is persistent dysbiosis of the microbial environment, altered immune and metabolic signaling can result in oxidative stress and the recruitment of immune cells which release reactive oxygen species (ROS), which may result in inflammationdriven carcinogenesis $(40,41)$. At present, the study of endometrial microbiota has reported that EC is associated with particular microorganisms (42). Similarly, related studies have also indicated that many microorganisms are involved in the development of EOC, such as Proteobacteria and Firmicutes (43). Brucella, Chlamydia, and Mycoplasma have been detected in over $60 \%$ of samples from those with EOC, and it is thought that the microbial dysbiosis may contribute to development of atypical epithelial cells showing hyperplasia and cytological atypia. These changes, along with genetic mutations in the ovaries gradually progress to EOC cells, particularly endometrioid and clear cell types (44-46). Figure 1 illustrates the potential carcinogenic mechanisms involved in the development of EOVC. Sophisticated proteomic tracing studies suggest that EOVC arises from the secretory cells of the endometrium or endometriosis, while OCCC tends to arise from ciliated cells (47). It is hypothesized that the unique microenvironment dictates the development of ciliated or secretory cells, which then gain sufficient mutations to become malignant (48).

\section{SYNCHRONOUS OVARIAN AND ENDOMETRIAL CARCINOMA}

Some women are diagnosed with EC and EOVC at the same time and it can be arduous to identify whether they demonstrate metastasizing focuses of a single tumor or if they have synchronous but relative independent primary tumor (49). If it is a secondary tumor, there is a question over how metastasis occurred, from the endometrium to the ovary or from the ovary to the endometrium. Researchers have begun to explore this question, but opinions currently differ and there are still controversies.

There is evidence that low-grade EOVC and EC are similar in both molecular and histological characteristics (49, 50). By comparing the mutant spectra of EOVC and EC (Table 2), many shared mutant genes have been identified: ARID1A, TP53, PTEN, PIK3CA, KRAS, CTNNB1, MMR, POLE, among others (51). However, the frequency of mutation of these genes appears to vary depending on different microenvironmental effects (50-60).

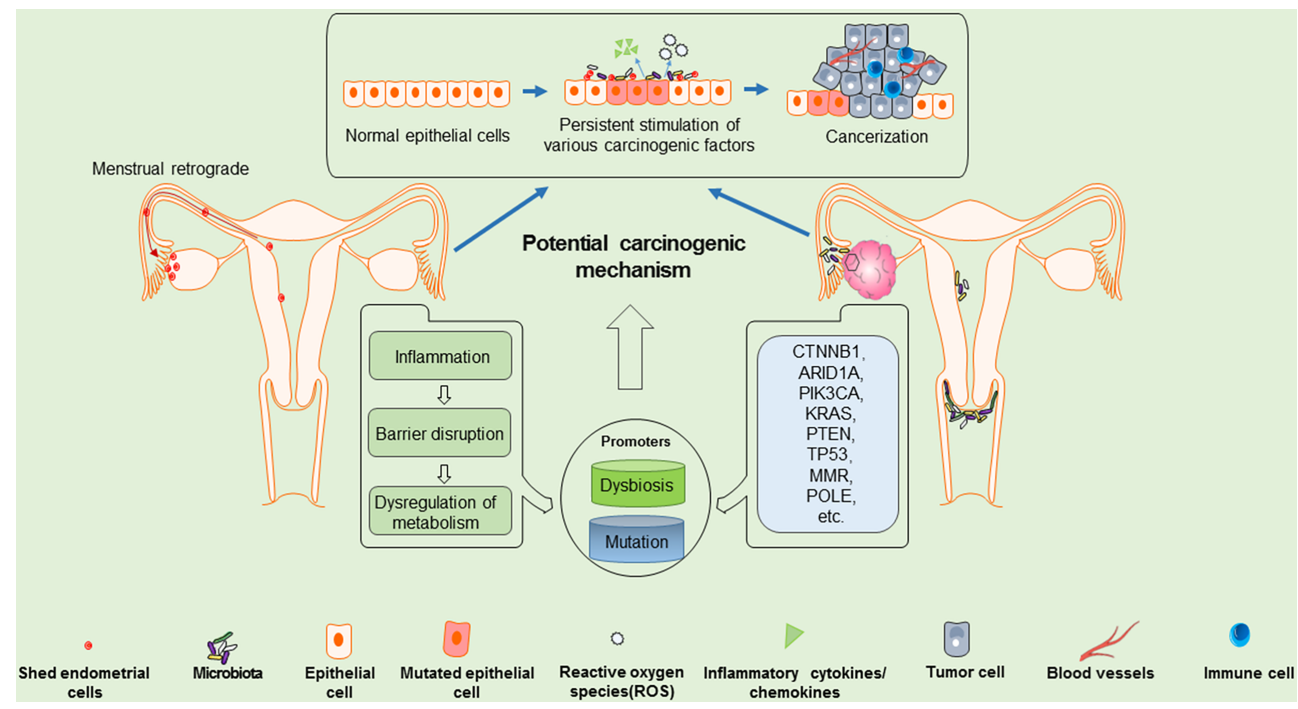

FIGURE 1 | Potential carcinogenic mechanisms of EOVC: shed endometrial cells may migrate retrogradely into the ovary, which may be a pro-factor for EOVC. Along with, microenvironment dysbiosis and accumulation of mutation burden, the shed endometrial cells and ovarian epithelial cells may gradually evolve into atypical cells, and further transform into carcinoma. 
TABLE 2 | Summary of most common molecular alterations in EOVC and EEC (50-60).

\begin{tabular}{lcc}
\hline Mutated genes & EOVC & EEC \\
\hline ARID1A & $30 \sim 55 \%$ & $39 \sim 55 \%$ \\
TP53 & $6 \sim 26 \%$ & $6 \sim 18 \%$ \\
PTEN & $14 \sim 29 \%$ & $64 \sim 80 \%$ \\
PIK3CA & $15 \sim 43 \%$ & $22 \sim 59 \%$ \\
KRAS & $12 \sim 26 \%$ & $19 \sim 43 \%$ \\
CTNNB1 & $16 \sim 63 \%$ & $16 \sim 28 \%$ \\
MMR & $7 \sim 18 \%$ & $7 \sim 28 \%$ \\
POLE & $3 \sim 10 \%$ & $7 \sim 15 \%$ \\
FBXW7 & $13 \%$ & - \\
SOX8 & $19 \%$ & - \\
PPP2R1A & $12 \sim 17 \%$ & - \\
ERBB2 & $8 \%$ & - \\
\hline
\end{tabular}

PTEN mutations are more frequent in low-grade endometrioid endometrial carcinoma (EEC) and CTNNB1 mutations are more common in low-grade EOVC (50). More patients with synchronous ovarian and uterine endometrioid carcinomas showed MLH1/ PMS2 deficiency and PTEN aberrations compared with isolated EOVC (53).

Synchronous tumors also have some commonly shared clinical characteristics: diagnosis tends to be at an earlier age and earlier stage, and prognosis is better compared with single primary ovarian or endometrial cancer $(6,61-63)$, although some studies have concluded that there is no difference in prognosis between a single primary carcinoma and synchronous tumors (64). One article has indicated that concurrent tumors are typically low-grade and confined to the uterine corpus and ovary, and that, despite being clonally related, behave much less aggressively than would be expected from a single advanced-stage cancer at either site (65). Moreover, a retrospective study comparing endometrial and ovarian synchronous primary cancers with ovarian metastases from EC, found that the synchronous primary cancer group typically had a history of endometriosis, the ovaries typically displayed a unilateral solid mass and the endometrial lesions were mostly non-vascularized; whereas the metastatic cancer group typically had bilateral solid ovarian masses (66). Synchronous EOVC and EC resulting from Lynch syndrome are concordant at a molecular level, suggesting a shared origins (67).

\section{MOLECULAR CHARACTERISTICS OF EOVC}

In terms of genomics, several unique heterogeneous genome profiles have been found in EOVC: CTNNB1, ARID1A, PIK3CA, KRAS, PTEN, TP53, MMR, POLE, SOX8, FBXW7, PPP2R1A, and ERBB2 $(5,68)$. A study investigating CTNNB1, a gene encoding $\beta$-Catenin protein, which participates in the Wnt signaling pathway, in EOVC patients showed that the rate of mutation is higher compared with that in EEC patients, and is associated with excellent clinical outcomes (69). This result contradicts other study findings in EEC which associate CTNNB1 mutations with a greater chance of recurrence (70).
Mutation of the ARID1A gene, which is mainly involved in the formation of the SWI/SNF chromatin complex, may be an early event in the transformation of endometriosis into cancer (26, 71). Presence of ARID1A mutations and loss of the ARID1Aencoded protein BAF250a are frequently observed events in EOVC, presenting in $36 \sim 48 \%$ of cases $(69,72)$. PIK3CA mutation and/or amplification, linked with a low FIGO stage and low-grade, and are frequently observed in EOVC. The amplification of PIK3CA can weaken therapeutic response to chemotherapy, and may serve as a marker to predict response to chemotherapy in $\operatorname{EOC}(73,74)$. KRAS mutations, which function to activate the MAPK pathway, play an important role in the development of endometriosis-associated cancer, including EOVC (75). PTEN loss is also a putative driver in EOC, and is associated with immunoresistance and poor response to programmed cell death protein 1 (PD-1) inhibitors. Downregulation of cytoplasmic PTEN expression is common in EOVC (76). Genomic data suggest that concurrent loss of PTEN and ARID1A with activating mutations of PIK3CA are involved in the pathogenesis of EOVC and OCCC. Abnormal expression of TP53 was also frequently seen in poorly differentiated endometrioid and clear cell tumors (77), being involved in several molecular subtypes of EOVC.

In addition to the more common genetic mutation events described above, mutations in mismatch repair (MMR) genes such as MLH1, MSH2, MSH6 and PMS2 form an important basis for the diagnosis of Lynch syndrome, Around 50\% of cases of Lynch syndrome are diagnosed at the onset of EC and OC (78, 79), mainly endometrioid and clear cell carcinoma (80-82). Women with Lynch syndrome have a lifetime risk of developing ovarian and endometrial cancers of $5.8 \sim 12 \%$ and $40 \sim 62 \%$, respectively $(78,83)$; with a further increased risk over the age of 40 (84). It has been reported in the literature that about $7 \sim 18 \%$ of cases of EOVC have MMR deficiency $(69,85)$, and this population also share similar characteristics: younger age $(<50$ years), higher CA125 at diagnosis, absence of ARID1A and higher FIGO stage $(85,86)$. Mutations of BRCA1/2 are wellknown as the most frequent mutations to occur in OC, mainly in high-grade serous ovarian carcinoma (HGSOC); however, reports of BRCA1/2 mutations in individual EOVC cases are not common. A study of EOC in Australian showed that 10 of 119 (8.4\%) women with EOVC have BRCA1/2 mutation and 8 of 10 EOVC were subsequently reclassified as serous or unspecified adenocarcinoma after strict histopathology review (87)

Although EOVC is less common than serous carcinoma, as an independent histological subtype, it is still difficult to diagnose clinically and is often confused with other types, such as HGSOC and mixed epithelial carcinoma. In particular, grade 3 EOVC may mimic HGSOC $(88,89)$. Therefore, knowing the gene mutation characteristics and whether cells have specific markers that other subtypes do not have will further help us to diagnose and study the disease (Table 3 ).

In proteomics, distinct markers may distinguish EOVC from other histological types. Serous tumor markers such as WT1, P53, CK20, and mucinous tumor markers such as CEA and MUC2 are not often expressed in EOVC and OCCC, and EOVC-specific 
TABLE 3 | The difference of immunohistochemistry $(\mathrm{IHC})$ between EOVC and HGSOC in clinical cases.

\begin{tabular}{lll}
\hline Types & Proportion (\%) & \multicolumn{1}{c}{ Tumor marker (determined by IHC) } \\
\hline EOVC & Most cases & WT1 (-); TP53 (wild-type); PR (+)/ER (+); Napsin-A (-) \\
& $10 \sim 30 \%$ & WT1 (+) and/or P53 (abn $\left.{ }^{\mathrm{a}}\right)$ \\
HGSOC & Most cases & WT1 (+); P53 (abn $) ; \mathrm{p} 16(+)^{\mathrm{b}}$
\end{tabular}

${ }^{a}$ null or $>70 \%$ expression of TP53; ${ }^{b}$ diffuse expression.

markers such as ER, PR, TFF3, DKK1, and MMP7 display nearexclusive expression in EOVC (90). Current studies have found that the status of WT1, P53, Napsin-A are helpful in reducing the rate of misdiagnosis of $\operatorname{EOVC}(88,89,91,92)$. The vast majority of low-grade EOVC are WT1(-), P53(wild-type), ER(+) or PR(+), Napsin-A(-) (3, 89, 91, 93-95), and about 10 30\% of EOVCs, especially high-grade EOVC, are WT1(+) or display abnormal P53 expression, which is easily confused with HGSOC (94, 96-98). Low-grade EOVC were characterized by strong nuclear $\beta$-catenin staining (99). Although controversial, high-grade EOVC may be considered to be a subtype of HGSOC according to immunophenotypic and gene profiling studies. In general, WT1 (+) and abnormal or absent P53 expression are highly suspicious for HGSOC $(96,100)$, but this does not mean that the classification is absolutely correct. Immunohistochemistry (IHC) is the only robust independent reference for OC histological subtypes (97).

\section{MOLECULAR TYPING OF EOVC}

The molecular typing of EC has become a conventional tool in guiding treatment for individuals and in stratifying cases in clinical trials $(101,102)$. EOVC and EEC, have many similarities in their molecular characteristics and histology and share the same molecular types. According to IHC and next-generation sequencing (NGS) technology, EOVC is divided into the following four groups (96): TP53 wild-type (TP53wt) group with no obvious abnormalities, which accounts for the largest proportion (51.2 73.2\%) of EOVC, followed by TP53 abnormal (TP53abn) group (9.6 24\%), MMR protein deficiency (MMRd) group (8.3 19.4\%), and the POLE hyper mutant (POLEmut) group $(2.8 \sim 10 \%)$ $(95,96)$ (Figure 2). In addition, tumors of the POLEmut and MMRd groups were less frequent in EOVC compared with those in $\operatorname{EC}(95,96,101)$. The distinction in the proportion of molecular classifications also reflects different microenvironments to some extent.

\section{POLE Mutation}

The POLE mutation is defined by pathogenic POLE exonuclease domain mutations that identify a group with an ultramutation phenotype. Somatic POLE exonuclease domain mutations occur early, quite possibly initiating events in sporadic cancers, and forcefully shape subsequent tumor evolution (104). Extreme genomic instability is characteristic of tumors with POLE mutations, with the mutation burden being among the highest found in human cancers. Tumors with
POLE mutations display a distinct mutational signature, lymphocytic infiltrate and have an excellent prognosis. Although patients with POLE mutations in EOVC have highrisk pathological features, the prognosis is the same as that of EC, which further validates the feasibility of this classification in EOVC (105).

\section{MMR Protein Deficiency (MMRd) Group}

The microsatellite instability (MSI) group is defined by deficiency of MMR (MLH1, MSH2, MSH6, or PMS2) proteins and identifies cases with microsatellite instability and a corresponding hypermutation phenotype. The MMRd group in EOVC is associated with a younger age and an increased number of tumor-infiltrating lymphocytes (4). The relationship between the MSI phenotype caused by the loss of MMR protein and Lynch syndrome has been clarified. This part of the population should be routinely screened for associated tumors to reduce the occurrence of non-ovarian malignant tumors (106).

\section{CN-High Group (TP53 Abnormal)}

The CN-high group (TP53 abnormal) is correlated with a high copy-number genomic phenotype and abnormal TP53 IHC staining pattern. EOVC patients with TP53 abnormalities had a higher frequency of poorly differentiated cells (G2/G3) (95) compared with other molecular types and have the worst prognosis. Research has reported that EOVC with abnormal TP53 may be the result of CTNNB1 mutation (95).

\section{CN-Low Group (TP53 Wild-Type)}

CN-low group (TP53 wild-type) comprises cases without any of the above three characteristics and is correlated with a copy-number low class. Research regarding the TP53wt group is relatively sparce due to its excellent survival state. In the context of TP53wt cases, in combination with CTNNB1 state (69), reveals that TP53wt (CTNNB1m) cases are almost always diagnosed at an early stage, rarely show macroscopic residual disease and have a low genomic complexity and low copy number alterations burden. However, the genomic complexity of TP53wt (CTNNB1wt) patients is relatively high compared with the TP53wt (CTNNB1m) group. Although the outcome of the TP53wt group is better, the difference in prognosis has not been fully explained and further study is still required.

Table 4 summarizes the published literature on the application of molecular typing of EC and EOVC. All published articles are based on data from the centers in Europe and the United States $(69,91,95,96,103)$, and distribution of four molecular types among other ethnic groups, especially Asians, should be further investigated in future studies.

\section{TUMOR MARKERS}

Tumor markers including serum CA125 and HE4, are reportedly useful for predicting malignancy in patients with pelvic masses. 


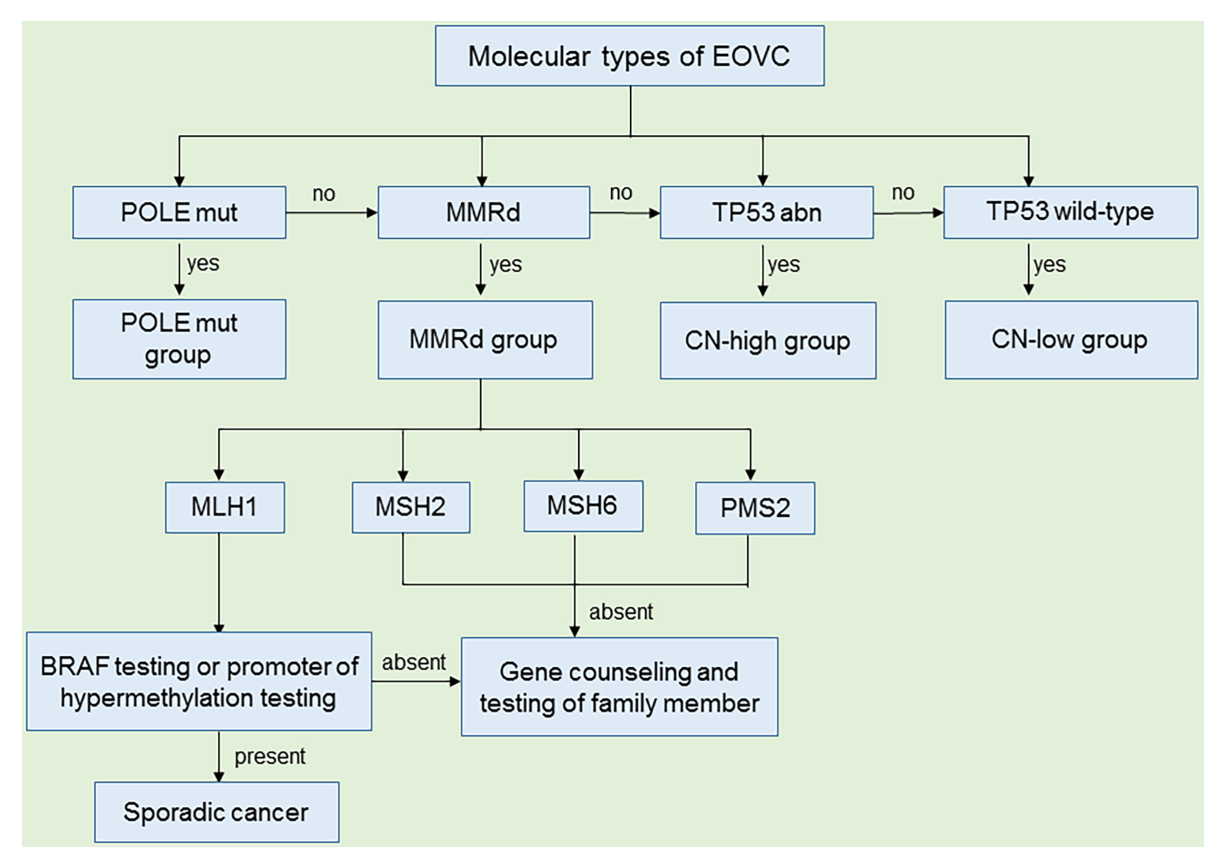

FIGURE 2 | Criteria for molecular typing of EOVC (103). All EOVC patients were grouped according to POLEmut, MMRd, TP53abn and TP53wild-type. For patients with MMR protein deficiency, after excluding sporadic cancers, genetic counseling and testing of family members are required to prevent hereditary cancers. (mut, mutation; d, deficiency; abn, abnormal).

TABLE 4 | Proportions of the four molecular subtypes of EOVC.

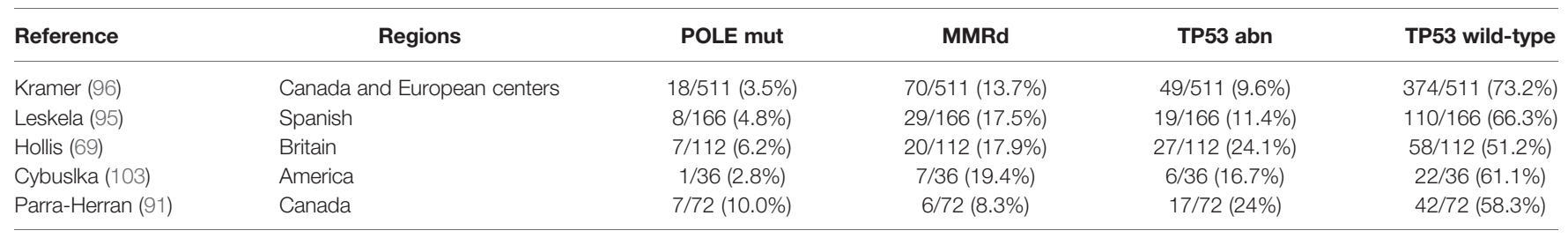

mut, mutation; d, deficiency; abn, abnormal.

Few studies have focused on the use of tumor markers in the preoperative diagnosis of EOVC. A case-control study demonstrated levels of serum CA19-9, sialyl Lewis-x antigen (SLX), carcinoembryogenic antigen (CEA), and lactate dehydrogenase (LDH) in EOVC are more likely to be higher compared with CA125 (107), however, more clinical studies are required to confirm this.

\section{METASTASIS}

Compared with EC and HGSOC, patients diagnosed with lowgrade EOVC seemingly have a lower rate of metastasis. However, this phenomenon is not an absolute event and clinically, there are still some people whose tumors metastasize. With regard to the synchronous discovery of EOVC and EC discussed previously, there is an ongoing controversy concerning if there are two independent primary tumors or if there has been metastatic formation. Generally speaking, metastatic of cancer generally indicates advanced disease or a very poor prognosis, while synchronous EOVC and EEC display the opposite, with limited tumors and a surprising prognosis $(108,109)$. Recently, Jennifer et al. revealed that in low-grade EEC, isolated ovarian metastases were not found, however, the incidence of ovarian metastases in patients with high-grade EEC ranged from 2 3\% (110). Whether the metastatic characteristics of EOVC are the same as those of EEC is worth further study. A retrospective study supported by several other papers $(111,112)$ found significantly higher ER positivity, but not PR positivity in EOVC without peritoneal metastases compared with cases with peritoneal metastases (93\% vs 59\%), suggesting ER positivity may be negatively associated with peritoneal metastases in EOVC (113).

In addition, there may be a relationship between microbial abnormality and cancer as mentioned above. In a mouse model of OC, the frequent use of antibiotics can lead to microbial 
dysbiosis, with a final outcome of accelerating the development and metastasis of OC (114).

\section{TREATMENT AND POTENTIAL THERAPY STRATEGIES}

The heterogeneity of EOC makes its treatment a challenge (115). Adjuvant therapy is universally dependent on grade and stage rather than histological type, consequently, it is necessary to implement the most appropriate treatment depending on the histological type of EOC (100).

According to the latest National Comprehensive Cancer Network (NCCN) guidelines (116), it is recommended that patients with low-grade (grade 1) EOVC should be followed these suggestions, observation is encouraged for stage IA/IB patients, similar to LGSOC; for patients with stage IC, observation or intravenous platinum-based therapy seems preferable; additionally, for women with high ER/PR expression of tumor cells, options to use hormonal therapy (tamoxifen, aromatase inhibitors); and patients with stage IIIV could be considered to accept systemic adjuvant chemotherapy following surgery. However, the treatment recommendations for grade $2 / 3$ EOVC are the same as HGSOC, employing paclitaxel and platinum-based chemotherapy after surgical resection as the mainstay of primary treatment. Although high-grade EOVC and HGSOC have equally high response rates to platinum-based chemotherapy, high-grade EOVC seems to develop chemoresistance easily at recurrence, indicating the significance for novel therapeutics in this subtype (115). Approximately $60 \%$ of patients with EOVC may exhibit potential therapeutic targets based on the available reports $(2,68)$.

At present, molecular typing of carcinoma is a popular topic, the purpose of which is to explore the clinical outcomes of different subgroups and further seek the most effective therapy strategy according to different molecular risk stratification. Over the past few years, molecular typing of EC has been proved to apply equally to EOVC, which provides a potential stratified therapy strategy. Although the concept of stratified treatment strategy has been proposed, specific stratified treatment plans are not raised. Furthermore, genomic analysis using targeted sequencing technology revealed clonality in synchronous EOVC and EC, which provides further clues to whether the patients of synchronous carcinoma require adjuvant chemotherapy $(117,118)$. ESMO-ESGO-ESTRO guidelines in 2015 provided a series of consensus on the management of EC, no adjuvant treatment is recommended for low-risk EEC patients with grade 1-2, stage I (119), similar to the NCCN guideline for early EOVC with grade 1 . Whether the treatment of early synchronous EOVC and EC follows the same recommendations or not, it's still further evaluated. Six cycles of carboplatin and paclitaxel as standard chemotherapy regime are also suitable for EC, which supported evidence for chemotherapy of advanced-stage synchronous EOVC and EC. If radiation therapy is suggested in patients with advanced synchronous ovarian and endometrial carcinoma, this could be given following chemotherapy (64). In some young EOVC patients undergoing fertility preservation treatments, endometrial sampling should be recommended to avoid a missed diagnosis of synchronous carcinoma (119).

In the previous section, we discussed the molecular characteristics of EOVC, nonetheless, therapeutic approaches targeting these molecular mutations and defects still require more clinical trials to evaluate and verify. Maintenance treatment using PARP inhibitors has a potentially important role in a significant subset of $\operatorname{EOVC}(120,121)$. ARID1A mutation will also equally enhance the sensibility of tumor cells to PARP inhibitors (122), indicating that patients with ARID1A mutation are also eligible to benefit from the use of PARP inhibitors, not just limited to patients with BRCA mutation. In addition to direct cytotoxic effects, PARP inhibitors also exhibit antitumor immunity (123, 124), combination of PARP inhibitors and immune checkpoint inhibitors for the therapy of EOC have obtained positive results in some clinical trials (125). Moreover, molecular mutations in other signal pathway (PI3K/AKT/mTOR, Wnt/ $\beta$ catenin/Tcf) may contribute to cell proliferation, invasion and migration, consequently, targeted inhibitors of such pathways may be able to overcome the limitations of single kinase inhibition and maybe useful in EOVC patients (126).

To change the ending of this disease, targeted therapy, immunotherapy and combination therapy are widely applied in EOC, as the new therapeutic strategies. EOC with MMR deficiency is more susceptible to the immunotherapies based on PD-1/PD-L1 pathway antibodies $(127,128)$, this kind of treatment may be valuable for patients with MMR deficient group of EOVC. In the same line, POLE gene damaging variants (129) and TP53 mutation (130) may also be correlated with the immunotherapeutic effect, this suggests that the combination of immune checkpoint inhibitor and certain pathway-targeted drugs may be a future direction for stratified therapy of EOVC patients. Besides, it's reported that the DGKAc-JUN-WEE1 signal pathway participates in the mechanism of platinum resistance in EOC patients (131), providing direction for targeted therapy to antagonize platinum resistance in the future study. Compared with effective but poorly tolerated concurrent therapy, Fang et al. found that sequential therapy with PARP and either WEE1 or ATR inhibitors is effective and less toxic in the study of EOC model (132). A phase II study published in 2016 showed that AZD1775, a WEE1 inhibitor, could sensitize the efficiency of carboplatin to some extent in the treatment of TP53-mutated EOC (133). Response to the immune checkpoint inhibitor could be associated with alteration of copy number and immunotherapy resistance may be apparent in EOC with high copy number alterations (134-136), but more research in the field is required in the future. Currently, the clinical trials of combination of immunotherapy with other treatment options are ongoing, combined therapies have collaborative effects in contrast to the use of a single treatment (137).

Many patients with low-grade EOVC have high expression of both ER and PR. Evidence for benefits of anti-estrogen 
treatments in ER-positive patients is accumulating, especially at a state of low tumor burden after primary chemotherapy or in the maintenance phase between chemotherapies (138). However, more studies are warranted to seek new biomarkers to help identify estrogen-responsive cancers more precisely (139). Endocrine therapy may also be a possible effective treatment attempt for patients with EOVC who have high PR positivity and don't accept systemic chemotherapy $(93,140,141)$ following primary surgical debulking. A study using cultured primary OC cells showed that about $60 \%$ of EOVC cells are PR(+), ER(+), and the survival ability of cancer cells after application of progesterone dropped significantly (142). Several patients with high-grade EOVC or advanced EOVC were treated with endocrine therapy and obtained encouraging therapeutic effects $(138,140)$. Even so, there is still very limited information on the sensitivity of EOVC to hormonal therapies, and further studies are warranted.

Interestingly, extensive evidence suggests that the human microbiome plays a crucial role in influencing cancer therapy, through modulating therapeutic response to treatment and mediating treatment-related toxicity $(143,144)$. The possibility of altering the microbiome as a therapeutic modality has been proposed, which may improve the immune system, activate antitumor response, and mediate chemotherapy resistance (114); this certainly deserves further investigation.

\section{PROGNOSIS AND INDEPENDENT PROGNOSTIC FACTORS}

Although the prognosis of EOVC is satisfactory compared with other histological subtypes, there are still big differences present when EOVC is further classified molecularly. In the analysis of prognosis, the TP53abn group has a poor prognosis, with a 10year disease-specific survival (DSS) of lower than 40\%; whereas the POLEmut group has the best prognosis among the four molecular subtypes. The prognoses of TP53wt group and MMRd are between those of the TP53abn and POLEmut groups (91, 96, 103). Moreover, previous studies have revealed a high frequency of recurrence and death among patients with tumors of the TP53abn group and whereas none of the patients carrying a POLE-mutated tumor had recurrence or died. TP53 wild-type group generally has a favorable prognosis, but some patients in the low-stage setting who did not accept adjuvant therapy did succumb to the disease suggesting there is actually an extensive spectrum of outcomes. Therefore additional biomarkers may be essential to identify specific patients in the TP53 wild-type group, who may have additional benefit from more aggressive management (96).

The major factors that affect the prognosis in univariate analysis were reported as the following: menopausal status, FIGO staging, histological grade, lymph node dissection, ascites cytology, and hormone receptor expression. The main factors that significantly affect prognosis in multivariate analysis are grade 3 and lymph node dissection $(111,145)$. Among them, FIGO staging is the most significant factor. Histologic grade was not a prognostic factor among early-stage EOVC in current studies $(96,146)$.

In a study comparing different differentiation levels of EOVC and HGSOC, it was found that most EOVC cases diagnosed as grade $1 / 2$ had a significantly better prognosis than those diagnosed with HGSOC, while the prognosis of grade 3 EOVC patients was not significantly different from that of HGSOC (147). This means that although the development of high-grade EOVC is rare, the poor prognosis requires attention and accurate diagnosis. For a female diagnosed with synchronous EOVC and $\mathrm{EC}$, the prognosis is better than that of a single locally advanced or metastatic tumor, and the recurrence risk is lower. After comparing whether or not to chemotherapy was administered after surgery, there is still no significant difference in survival benefit in those with synchronous tumors (148), the prognosis is poor if the myometrium is invaded; while the impact of lymph node metastasis and peritoneal dissemination on survival has no statistical difference (148).

The prognostic value of many other biomarkers was also evaluated in EOVC (Table 5). High expression of PR and/or ER in EOVC patients has been shown in several articles as a favorable prognosis factor $(93,111,112)$. ARID1A, $\beta$ Catenin, and TP53 could be used with conventional clinical and histological factors to predict the prognosis of patients with EOVC (77). Meanwhile, expression of CDX2 and nuclear $\beta$ Catenin independently or in combination appear to be positive prognostic factors (149). SATB2 expression is also an independent marker for improved progression-free survival for EOVC cases, especially for advanced patients (150). In patients with FIGO stage I II EOVC, CTNNB1 mutations and nuclear $\beta$-catenin expression are associated with a better prognosis (disease-free survival), in contrast to a worse prognosis in EEC (56). P16 block expression in EOVC cases is more frequently found in the worse prognosis stage III/IV and grade 3 cases (151). Other novel prognostic biomarkers for early-stage EOVC have been reported, recently, an article was first to publish evidence of a connection between CECR1, $\mathrm{KIF} 26 \mathrm{~B}$, and PIK3CA protein expression and prognosis in EOVC (152). More biomarkers should be included in the study of prognosis.

TABLE 5 | Possible factors affecting EOVC prognosis.

\begin{tabular}{ll}
\hline & \multicolumn{1}{c}{ Possible factors } \\
\hline Favorable & Stage I/II or grade1/2 \\
prognosis & ER expression and/or PR expression \\
& SATB2 expression \\
& Nuclear ARID1A positive expression \\
& CTNNB1 mutations and nuclear $\beta$-catenin expression \\
& Nuclear/-catenin and CDX2 expression individually or in \\
& Combination \\
Stage III/IV or grade 3 \\
Prognosis & P16-block expression \\
& Nuclear ARID1A negative expression (BAF250a loss) \\
& Negative protein expression of CECR1, KIF26B, and \\
& PIK3CA
\end{tabular}




\section{CONCLUSION AND IMPLICATIONS FOR THE FUTURE}

In conclusion, compared with HGSOC and other histologic types of EOC, EOVC displays distinct molecular characteristics and has a better prognosis. Persistent existence of microbial dysbiosis in the upper reproductive tract has been suggested to play a role in the development of carcinogenesis, and hence there are promises to provide unique and interesting insights and guidance into health and disease in follow-up studies. Moreover, although the prognostics significance of molecular classification remains to be demonstrated, it has important therapeutic implications in the context of the popularity of targeted therapy and immunotherapy. Thus, in females with EOVC, further individualized treatment according to biomarker and classification may be valuable to improve prognosis and quality of life.

\section{AUTHOR CONTRIBUTIONS}

$\mathrm{YZ}$ conceived the project. SC and YL reviewed the literature and drafted the article. SD and LL contributed to classifying the literature, LQ revised the manuscript. WX and YZ

\section{REFERENCES}

1. Bray F, Ferlay J, Soerjomataram I, Siegel RL, Torre LA, Jemal A. Global Cancer Statistics 2018: GLOBOCAN Estimates of Incidence and Mortality Worldwide for 36 Cancers in 185 Countries. CA: A Cancer J Clin (2018) 68:394-424. doi: 10.3322/caac.21492

2. Alexandrova E, Pecoraro G, Sellitto A, Melone V, Ferravante C, Rocco T, et al. An Overview of Candidate Therapeutic Target Genes in Ovarian Cancer. Cancers (Basel) (2020) 12:1470. doi: 10.3390/cancers 12061470

3. Anglesio MS, Yong PJ. Endometriosis-Associated Ovarian Cancers. Clin Obstet Gynecol (2017) 60:711-27. doi: 10.1097/GRF.0000000000000320

4. Leskela S, Romero I, Cristobal E, Pérez-Mies B, Rosa-Rosa JM, GutierrezPecharroman A. Mismatch Repair Deficiency in Ovarian Carcinoma: Frequency, Causes, and Consequences. Am J Surg Pathol (2020) 44:64956. doi: 10.1097/PAS.0000000000001432

5. Matias-Guiu X, Stewart CJR. Endometriosis-Associated Ovarian Neoplasia. Pathology (2018) 50:190-204. doi: 10.1016/j.pathol.2017.10.006

6. Chiang YC, Chen CA, Huang CY, Hsieh CY, Cheng WF. Synchronous Primary Cancers of the Endometrium and Ovary. Int J Gynecol Cancer (2008) 18:159-64. doi: 10.1111/j.1525-1438.2007.00975.x

7. Torre LA, Trabert B, DeSantis CE, Miller KD, Samimi G, Runowicz CD, et al. Ovarian Cancer Statistics, 2018. CA Cancer J Clin (2018) 68:284-96. doi: $10.3322 /$ caac. 21456

8. Winterhoff B, Hamidi H, Wang C, Kalli KR, Fridley BL, Dering J, et al. Molecular Classification of High Grade Endometrioid and Clear Cell Ovarian Cancer Using TCGA Gene Expression Signatures. Gynecol Oncol (2016) 141:95-100. doi: 10.1016/j.ygyno.2016.02.023

9. Coburn SB, Bray F, Sherman ME, Trabert B. International Patterns and Trends in Ovarian Cancer Incidence, Overall and by Histologic Subtype. Int J Cancer (2017) 140:2451-60. doi: 10.1002/ijc.30676

10. Wentzensen N, Poole EM, Trabert B, White E, Arslan AA, Patel AV, et al. Ovarian Cancer Risk Factors by Histologic Subtype: An Analysis From the Ovarian Cancer Cohort Consortium. J Clin Oncol (2016) 34:2888-98. doi: $10.1200 /$ JCO.2016.66.8178

11. Pearce CL, Templeman C, Rossing MA, Lee A, Near AM, Webb PM, et al. Association Between Endometriosis and Risk of Histological Subtypes of contributed to funding and general oversight of the project. All authors contributed to the article and approved the submitted version.

\section{FUNDING}

This work was supported by National Key Research and Development Program (2018YFC1003900), the National Natural Science Foundation of China (81872110, 81902632), the Strategic Priority Research Program of the Chinese Academy of Sciences (XDB29030000), the Ministry of Science and Technology of China (2016YFC1303503), and the Fundamental Research Funds for the Central Universities (WK9110000104). The funders had no role in the study design, data collection and analysis, decision to publish, or preparation of the manuscript.

\section{ACKNOWLEDGMENTS}

We would like to thank TopEdit (www.topeditsci.com) for its linguistic assistance during the preparation of this manuscript.

Ovarian Cancer: A Pooled Analysis of Case-Control Studies. Lancet Oncol (2012) 13:385-94. doi: 10.1016/s1470-2045(11)70404-1

12. Momenimovahed Z, Tiznobaik A, Taheri S, Salehiniya H. Ovarian Cancer in the World: Epidemiology and Risk Factors. Int J Womens Health (2019) 11:287-99. doi: 10.2147/IJWH.S197604

13. Reid BM, Permuth JB, Sellers TA. Epidemiology of Ovarian Cancer: A Review. Cancer Biol Med (2017) 14:9-32. doi: 10.20892/j.issn.2095-3941.2016.0084

14. Kurian AW, Balise RR, McGuire V, Whittemore AS. Histologic Types of Epithelial Ovarian Cancer: Have They Different Risk Factors? Gynecol Oncol (2005) 96:520-30. doi: 10.1016/j.ygyno.2004.10.037

15. Xu J, Peng JJ, Yang W, Fu K, Zhang Y. Vaginal Microbiomes and Ovarian Cancer: A Review. Am J Cancer Res (2020) 10:743-56.

16. Symons LK, Miller JE, Kay VR, Marks RM, Liblik K, Koti M, et al. The Immunopathophysiology of Endometriosis. Trends Mol Med (2018) 24:74862. doi: 10.1016/j.molmed.2018.07.004

17. SJ A. Metastatic or Embolic Endometriosis, Due to the Menstrual Dissemination of Endometrial Tissue Into the Venous Circulation. Am J Pathol (1927) 3:93-110.

18. Barreta A, Sarian L, Ferracini AC, Eloy L, Brito ABC, de Angelo Andrade L, et al. Endometriosis-Associated Ovarian Cancer: Population Characteristics and Prognosis. Int J Gynecol Cancer (2018) 28:1251-7. doi: 10.1097/ IGC.0000000000001317

19. Bulun SE, Wan Y, Matei D. Epithelial Mutations in Endometriosis: Link to Ovarian Cancer. Endocrinology (2019) 160:626-38. doi: 10.1210/en.201800794

20. Murakami K, Kotani Y, Nakai H, Matsumura N. Endometriosis-Associated Ovarian Cancer: The Origin and Targeted Therapy. Cancers (Basel) (2020) 12:1676. doi: 10.3390/cancers 12061676

21. Zhang W, Jia S, Xiang Y, Yang J, Jia C, Leng J. Comparative Study of Endometrioid Borderline Ovarian Tumor With and Without Endometriosis. J Ovarian Res (2018) 11:67. doi: 10.1186/s13048-018-0440-x

22. Anglesio MS, Papadopoulos N, Ayhan A, Nazeran TM, Noe M, Horlings $\mathrm{HM}$, et al. Cancer-Associated Mutations in Endometriosis Without Cancer. N Engl J Med (2017) 376:1835-48. doi: 10.1056/NEJMoa1614814

23. Suda K, Nakaoka H, Yoshihara K, Ishiguro T, Tamura R, Mori Y, et al Clonal Expansion and Diversification of Cancer-Associated Mutations in 
Endometriosis and Normal Endometrium. Cell Rep (2018) 24:1777-89. doi: 10.1016/j.celrep.2018.07.037

24. Melin A, Sparén P, Persson I, Bergqvist A. Endometriosis and the Risk of Cancer With Special Emphasis on Ovarian Cancer. Hum Reprod (2006) 21:1237-42. doi: 10.1093/humrep/dei462

25. Yamamoto S, Tsuda H, Takano M, Tamai S, Matsubara O. Loss of ARID1A Protein Expression Occurs as an Early Event in Ovarian Clear-Cell Carcinoma Development and Frequently Coexists With PIK3CA Mutations. Mod Pathol (2012) 25:615-24. doi: 10.1038/modpathol.2011.189

26. Wiegand KC, Shah SP, Al-Agha OM, Zhao Y, Tse K, Zeng T, et al. ARID1A Mutations in Endometriosis-Associated Ovarian Carcinomas. N Engl J Med (2010) 363:1532-43. doi: 10.1056/NEJMoa1008433

27. van Dam PA, Verhoeven Y, Trinh XB, Wouters A, Lardon F, Prenen H, et al. RANK/RANKL Signaling Inhibition may Improve the Effectiveness of Checkpoint Blockade in Cancer Treatment. Crit Rev Oncol/Hematol (2019) 133:85-91. doi: 10.1016/j.critrevonc.2018.10.011

28. Renema N, Navet B, Heymann MF, Lezot F, Heymann D. Rank-RANKL Signalling in Cancer. Biosci Rep (2016) 36:e00366. doi: 10.1042/ BSR20160150

29. Gregori E, Rodríguez-García V, Martínez J, Burgués O, Tarín JJ, Cano A, et al. Differential Expression of Receptor Activator of Nuclear Factor Kappa B in Healthy Endometrium, Ovarian Endometrioma, and Endometrioid Ovarian Cancer. Am J Obstetr Gynecol (2020) 222:279-81. doi: 10.1016/ j.ajog.2019.11.1259

30. Anglesio MS, Bashashati A, Wang YK, Senz J, Ha G, Yang W, et al. Multifocal Endometriotic Lesions Associated With Cancer are Clonal and Carry a High Mutation Burden. J Pathol (2015) 236:201-9. doi: 10.1002/ path. 4516

31. Ren T, Wang S, Sun J, Qu JM, Xiang Y, Shen K, et al. Endometriosis is the Independent Prognostic Factor for Survival in Chinese Patients With Epithelial Ovarian Carcinoma. J Ovarian Res (2017) 10:67. doi: 10.1186/ s13048-017-0363-y

32. Paik ES, Kim TJ, Choi CH, Kim BG, Bae DS, Lee JW. Clinical Outcomes of Patients With Clear Cell and Endometrioid Ovarian Cancer Arising From Endometriosis. J Gynecol Oncol (2018) 29:e18. doi: 10.3802/jgo.2018.29.e18

33. Kim HS, Kim TH, Chung HH, Song YS. Risk and Prognosis of Ovarian Cancer in Women With Endometriosis: A Meta-Analysis. Br J Cancer (2014) 110:1878-90. doi: 10.1038/bjc.2014.29

34. Mikhaleva LM, Davydov AI, Patsap OI, Mikhaylenko EV, Nikolenko VN, Neganova ME, et al. Malignant Transformation and Associated Biomarkers of Ovarian Endometriosis: A Narrative Review. Adv Ther (2020) 37:2580603. doi: 10.1007/s12325-020-01363-5

35. Chen C, Song X, Wei W, Zhong H, Dai J, Lan Z, et al. The Microbiota Continuum Along the Female Reproductive Tract and its Relation to Uterine-Related Diseases. Nat Commun (2017) 8:875. doi: 10.1038/s41467017-00901-0

36. Walther-Antonio MR, Chen J, Multinu F, Hokenstad A, Distad TJ, Cheek $\mathrm{EH}$, et al. Potential Contribution of the Uterine Microbiome in the Development of Endometrial Cancer. Genome Med (2016) 8:122. doi: 10.1186/s13073-016-0368-y

37. Laniewski P, Ilhan ZE, Herbst-Kralovetz MM. The Microbiome and Gynaecological Cancer Development, Prevention and Therapy. Nat Rev Urol (2020) 17:232-50. doi: 10.1038/s41585-020-0286-z

38. Molina NM, Sola-Leyva A, Saez-Lara MJ, Plaza-Diaz J, Tubic-Pavlovic A, Romero B, et al. New Opportunities for Endometrial Health by Modifying Uterine Microbial Composition: Present or Future? Biomolecules (2020) 10:593. doi: 10.3390/biom10040593

39. Riganelli L, Iebba V, Piccioni M, Illuminati I, Bonfiglio G, Neroni B, et al. Structural Variations of Vaginal and Endometrial Microbiota: Hints on Female Infertility. Front Cell Infect Microbiol (2020) 10:350. doi: 10.3389/ fcimb. 2020.00350

40. Chew SS, Tan LT, Law JW, Pusparajah P, Goh BH, Ab Mutalib NS, et al. Targeting Gut Microbial Biofilms-A Key to Hinder Colon Carcinogenesis? Cancers (Basel) (2020) 12:2272. doi: 10.3390/cancers12082272

41. Frick A, Khare V, Paul G, Lang M, Ferk F, Knasmuller S, et al. Overt Increase of Oxidative Stress and DNA Damage in Murine and Human Colitis and Colitis-Associated Neoplasia. Mol Cancer Res (2018) 16:634-42. doi: 10.1158/1541-7786.MCR-17-0451
42. Lu W, He F, Lin Z, Liu S, Tang L, Huang Y, et al. Dysbiosis of the Endometrial Microbiota and its Association With Inflammatory Cytokines in Endometrial Cancer. Int J Cancer (2021) 148:1708-16. doi: 10.1002/ ijc. 33428

43. Nené NR, Reisel D, Leimbach A, Franchi D, Jones A, Evans I, et al. Association Between the Cervicovaginal Microbiome, BRCA1 Mutation Status, and Risk of Ovarian Cancer: A Case-Control Study. Lancet Oncol (2019) 20:1171-82. doi: 10.1016/s1470-2045(19)30340-7

44. Mari-Alexandre J, Carcelen AP, Agababyan C, Moreno-Manuel A, GarciaOms J, Calabuig-Farinas S, et al. Interplay Between MicroRNAs and Oxidative Stress in Ovarian Conditions With a Focus on Ovarian Cancer and Endometriosis. Int J Mol Sci (2019) 20:5322. doi: 10.3390/ijms20215322

45. Heidemann LN, Hartwell D, Heidemann CH, Jochumsen KM. The Relation Between Endometriosis and Ovarian Cancer - a Review. Acta Obstet Gynecol Scand (2014) 93:20-31. doi: 10.1111/aogs.12255

46. Munksgaard PS, Blaakaer J. The Association Between Endometriosis and Ovarian Cancer: A Review of Histological, Genetic and Molecular Alterations. Gynecol Oncol (2012) 124:164-9. doi: 10.1016/j.ygyno.2011.10.001

47. Cochrane DR, Tessier-Cloutier B, Lawrence KM, Nazeran T, Karnezis AN, Salamanca C, et al. Clear Cell and Endometrioid Carcinomas: Are Their Differences Attributable to Distinct Cells of Origin? J Pathol (2017) 243:2636. doi: $10.1002 /$ path. 4934

48. Wendel JRH, Wang X, Hawkins SM. The Endometriotic Tumor Microenvironment in Ovarian Cancer. Cancers (Basel) (2018) 10:261. doi: $10.3390 /$ cancers 10080261

49. Rodolakis A, Thomakos N, Akrivos N, Sotiropoulou M, Ioannidis I, Haidopoulos D, et al. Clinicopathologic Insight of Simultaneously Detected Primary Endometrial and Ovarian Carcinomas. Arch Gynecol Obstetr (2011) 285:817-21. doi: 10.1007/s00404-011-2046-Z

50. McConechy MK, Ding J, Senz J, Yang W, Melnyk N, Tone AA, et al. Ovarian and Endometrial Endometrioid Carcinomas Have Distinct CTNNB1 and PTEN Mutation Profiles. Mod Pathol (2014) 27:128-34. doi: 10.1038/ modpathol.2013.107

51. Reijnen C, Kusters-Vandevelde HVN, Ligtenberg MJL, Bulten J, Oosterwegel M, Snijders M, et al. Molecular Profiling Identifies Synchronous Endometrial and Ovarian Cancers as Metastatic Endometrial Cancer With Favorable Clinical Outcome. Int $J$ Cancer (2020) 147:478-89. doi: 10.1002/ijc.32907

52. Toumpeki C, Liberis A, Tsirkas I, Tsirka T, Kalagasidou S, Inagamova L, et al. The Role of ARID1A in Endometrial Cancer and the Molecular Pathways Associated With Pathogenesis and Cancer Progression. In Vivo (2019) 33:659-67. doi: 10.21873/invivo.11524

53. Kelemen LE, Rambau PF, Koziak JM, Steed H, Kobel M. Synchronous Endometrial and Ovarian Carcinomas: Predictors of Risk and Associations With Survival and Tumor Expression Profiles. Cancer Causes Control (2017) 28:447-57. doi: 10.1007/s10552-017-0855-5

54. Takeda T, Banno K, Okawa R, Yanokura M, Iijima M, Irie-Kunitomi H, et al. ARID1A Gene Mutation in Ovarian and Endometrial Cancers (Review). Oncol Rep (2016) 35:607-13. doi: 10.3892/or.2015.4421

55. Cancer Genome Atlas Research N, Kandoth C, Schultz N, Cherniack AD, Akbani R, Liu Y, et al. Integrated Genomic Characterization of Endometrial Carcinoma. Nature (2013) 497:67-73. doi: 10.1038/nature12113

56. Zyla RE, Olkhov-Mitsel E, Amemiya Y, Bassiouny D, Seth A, Djordjevic B, et al. Ctnnb1 Mutations and Aberrant $\beta$-Catenin Expression in Ovarian Endometrioid Carcinoma: Correlation With Patient Outcome. Am J Surg Pathol (2021) 45:68-76. doi: 10.1097/PAS.0000000000001553

57. Liu Y, Patel L, Mills GB, Lu KH, Sood AK, Ding L, et al. Clinical Significance of CTNNB1 Mutation and Wnt Pathway Activation in Endometrioid Endometrial Carcinoma. J Natl Cancer Inst (2014) 106:dju245. doi: 10.1093/jnci/dju245

58. Bolivar AM, Luthra R, Mehrotra M, Chen W, Barkoh BA, Hu P, et al. Targeted Next-Generation Sequencing of Endometrial Cancer and Matched Circulating Tumor DNA: Identification of Plasma-Based, Tumor-Associated Mutations in Early Stage Patients. Mod Pathol (2019) 32:405-14. doi: 10.1038/s41379-018-0158-8

59. Palmirotta R, Silvestris E, D’Oronzo S, Cardascia A, Silvestris F. Ovarian Cancer: Novel Molecular Aspects for Clinical Assessment. Crit Rev Oncol Hematol (2017) 117:12-29. doi: 10.1016/j.critrevonc.2017.06.007 
60. Romero I, Leskela S, Mies BP, Velasco AP, Palacios J. Morphological and Molecular Heterogeneity of Epithelial Ovarian Cancer: Therapeutic Implications. EJC Suppl (2020) 15:1-15. doi: 10.1016/j.ejcsup.2020.02.001

61. Schultheis AM, Ng CK, De Filippo MR, Piscuoglio S, Macedo GS, Gatius S, et al. Massively Parallel Sequencing-Based Clonality Analysis of Synchronous Endometrioid Endometrial and Ovarian Carcinomas. J Natl Cancer Inst (2016) 108:djv427. doi: 10.1093/jnci/djv427

62. Lim YK, Padma R, Foo L, Chia YN, Yam P, Chia J, et al. Survival Outcome of Women With Synchronous Cancers of Endometrium and Ovary: A 10 Year Retrospective Cohort Study. J Gynecol Oncol (2011) 22:239-43. doi: 10.3802/ jgo.2011.22.4.239

63. Khalid N, Ullah F, Zafar H, Anwer AW, Abbas T, Shakeel O, et al. Synchronous Primary Endometrial and Ovarian Cancers: Trends and Outcomes of the Rare Disease at a South Asian Tertiary Care Cancer Center. Cureus (2020) 12:e9163. doi: 10.7759/cureus.9163

64. Heitz F, Amant F, Fotopoulou C, Battista MJ, Wimberger P, Traut A, et al. Synchronous Ovarian and Endometrial Cancer-an International Multicenter Case-Control Study. Int J Gynecol Cancer (2014) 24:54-60. doi: 10.1097/IGC.0000000000000019

65. Gilks CB, Kommoss F. Synchronous Tumours of the Female Reproductive Tract. Pathology (2018) 50:214-21. doi: 10.1016/j.pathol.2017.10.007

66. Moro F, Leombroni M, Pasciuto T, Trivellizzi IN, Mascilini F, Ciccarone F, et al. Synchronous Primary Cancers of Endometrium and Ovary vs Endometrial Cancer With Ovarian Metastasis: An Observational Study. Ultrasound Obstet Gynecol (2019) 53:827-35. doi: 10.1002/uog.20213

67. Niskakoski A, Pasanen A, Porkka N, Eldfors S, Lassus H, Renkonen-Sinisalo L, et al. Converging Endometrial and Ovarian Tumorigenesis in Lynch Syndrome: Shared Origin of Synchronous Carcinomas. Gynecol Oncol (2018) 150:92-8. doi: 10.1016/j.ygyno.2018.04.566

68. Pierson WE, Peters PN, Chang MT, Chen LM, Quigley DA, Ashworth A, et al. An Integrated Molecular Profile of Endometrioid Ovarian Cancer. Gynecol Oncol (2020) 157:55-61. doi: 10.1016/j.ygyno.2020.02.011

69. Hollis RL, Thomson JP, Stanley B, Churchman M, Meynert AM, Rye T, et al. Molecular Stratification of Endometrioid Ovarian Carcinoma Predicts Clinical Outcome. Nat Commun (2020) 11:4995. doi: 10.1038/s41467-02018819-5

70. Kurnit KC, Kim GN, Fellman BM, Urbauer DL, Mills GB, Zhang W, et al. CTNNB1 (Beta-Catenin) Mutation Identifies Low Grade, Early Stage Endometrial Cancer Patients at Increased Risk of Recurrence. Mod Pathol (2017) 30:1032-41. doi: 10.1038/modpathol.2017.15

71. Ayhan A, Mao TL, Seckin T, Wu CH, Guan B, Ogawa H, et al. Loss of ARID1A Expression is an Early Molecular Event in Tumor Progression From Ovarian Endometriotic Cyst to Clear Cell and Endometrioid Carcinoma. Int J Gynecol Cancer (2012) 22:1310-5. doi: 10.1097/ IGC.0b013e31826b5dcc

72. Lowery WJ, Schildkraut JM, Akushevich L, Bentley R, Marks JR, Huntsman D, et al. Loss of ARID1A-associated Protein Expression is a Frequent Event in Clear Cell and Endometrioid Ovarian Cancers. Int J Gynecol Cancer (2012) 22:9-14. doi: 10.1097/IGC.0b013e318231f140

73. Kolasa IK, Rembiszewska A, Felisiak A, Ziolkowska-Seta I, Murawska M, Moes J, et al. PIK3CA Amplification Associates With Resistance to Chemotherapy in Ovarian Cancer Patients. Cancer Biol Ther (2009) 8:216. doi: 10.4161/cbt.8.1.7209

74. Nakamura M, Obata T, Daikoku T, Fujiwara H. The Association and Significance of p53 in Gynecologic Cancers: The Potential of Targeted Therapy. Int J Mol Sci (2019) 20:5482. doi: 10.3390/ijms20215482

75. Stewart CJ, Leung Y, Walsh MD, Walters RJ, Young JP, Buchanan DD. KRAS Mutations in Ovarian Low-Grade Endometrioid Adenocarcinoma: Association With Concurrent Endometriosis. Hum Pathol (2012) 43:117783. doi: 10.1016/j.humpath.2011.10.009

76. Martins FC, Couturier DL, Paterson A, Karnezis AN, Chow C, Nazeran TM, et al. Clinical and Pathological Associations of PTEN Expression in Ovarian Cancer: A Multicentre Study From the Ovarian Tumour Tissue Analysis Consortium. Br J Cancer (2020) 123:793-802. doi: 10.1038/s41416-0200900-0

77. Heckl M, Schmoeckel E, Hertlein L, Rottmann M, Jeschke U, Mayr D. The ARID1A, p53 and $\beta$-Catenin Statuses are Strong Prognosticators in Clear
Cell and Endometrioid Carcinoma of the Ovary and the Endometrium. PloS One (2018) 13:e0192881. doi: 10.1371/journal.pone.0192881

78. Nakamura K, Banno K, Yanokura M, Iida M, Adachi M, Masuda K, et al. Features of Ovarian Cancer in Lynch Syndrome (Review). Mol Clin Oncol (2014) 2:909-16. doi: 10.3892/mco.2014.397

79. KH LU, Daniels M. Endometrial and Ovarian Cancer in Women With Lynch Syndrome: Update in Screening and Prevention. Fam Cancer (2013) 12:273-7. doi: 10.1007/s10689-013-9664-5

80. Chui MH, Ryan P, Radigan J, Ferguson SE, Pollett A, Aronson M. The Histomorphology of Lynch Syndrome- Associated Ovarian Carcinomas Toward a Subtype-Specific Screening Strategy. Am J Surg Pathol (2014) 38:1173-81. doi: 10.1097/PAS.0000000000000298

81. Chui MH, Gilks CB, Cooper K, Clarke BA. Identifying Lynch Syndrome in Patients With Ovarian Carcinoma: The Significance of Tumor Subtype. Adv Anat Pathol (2013) 20:378-86. doi: 10.1097/PAP.0b013e3182a92cf8

82. Ryan NAJ, Evans DG, Green K, Crosbie EJ. Pathological Features and Clinical Behavior of Lynch Syndrome-Associated Ovarian Cancer. Gynecol Oncol (2017) 144:491-5. doi: 10.1016/j.ygyno.2017.01.005

83. Lancaster JM, Powell CB, Chen LM, Richardson DLCommittee SGOCP. Society of Gynecologic Oncology Statement on Risk Assessment for Inherited Gynecologic Cancer Predispositions. Gynecol Oncol (2015) 136:3-7. doi: 10.1016/j.ygyno.2014.09.009

84. Dominguez-Valentin M, Sampson JR, Seppala TT, Ten Broeke SW, Plazzer JP, Nakken S, et al. Cancer Risks by Gene, Age, and Gender in 6350 Carriers of Pathogenic Mismatch Repair Variants: Findings From the Prospective Lynch Syndrome Database. Genet Med (2020) 22:15-25. doi: 10.1038/ s41436-019-0596-9

85. Aysal A, Karnezis A, Medhi I, Grenert JP, Zaloudek CJ, Rabban JT. Ovarian Endometrioid Adenocarcinoma: Incidence and Clinical Significance of the Morphologic and Immunohistochemical Markers of Mismatch Repair Protein Defects and Tumor Microsatellite Instability. Am J Surg Pathol (2012) 36:163-72. doi: 10.1097/PAS.0b013e31823bc434

86. Rambau PF, Duggan MA, Ghatage P, Warfa K, Steed H, Perrier R, et al. Significant Frequency of MSH2/MSH6 Abnormality in Ovarian Endometrioid Carcinoma Supports Histotype-Specific Lynch Syndrome Screening in Ovarian Carcinomas. Histopathology (2016) 69:288-97. doi: $10.1111 /$ his. 12934

87. Alsop K, Fereday S, Meldrum C, deFazio A, Emmanuel C, George J. BRCA Mutation Frequency and Patterns of Treatment Response in BRCA Mutation-Positive Women With Ovarian Cancer: A Report From the Australian Ovarian Cancer Study Group. J Clin Oncol: Off J Am Soc Clin Oncol (2012) 30:2654-63. doi: 10.1200/JCO.2011.39.8545

88. Assem H, Rambau PF, Lee S, Ogilvie T, Sienko A, Kelemen LE, et al. HighGrade Endometrioid Carcinoma of the Ovary: A Clinicopathologic Study of 30 Cases. Am J Surg Pathol (2018) 42:534-44. doi: 10.1097/PAS. 0000000000001016

89. Lim D, Murali R, Murray MP, Veras E, Park KJ, Soslow RA. Morphological and Immunohistochemical Reevaluation of Tumors Initially Diagnosed as Ovarian Endometrioid Carcinoma With Emphasis on High-grade Tumors. Am J Surg Pathol (2016) 40:302-12. doi: 10.1097/PAS.0000000000000550

90. Leung F, Bernardini MQ, Liang K, Batruch I, Rouzbahman M, Diamandis EP, et al. Unraveling Endometriosis-Associated Ovarian Carcinomas Using Integrative Proteomics. F1000Res (2018) 7:189. doi: 10.12688/ f1000research.13863.2

91. Parra-Herran C, Lerner-Ellis J, Xu B, Khalouei S, Bassiouny D, Cesari M, et al. Molecular-Based Classification Algorithm for Endometrial Carcinoma Categorizes Ovarian Endometrioid Carcinoma Into Prognostically Significant Groups. Mod Pathol (2017) 30:1748-59. doi: 10.1038/ modpathol.2017.81

92. Madore J, Ren F, Filali-Mouhim A, Sanchez L, Kobel M, Tonin PN, et al. Characterization of the Molecular Differences Between Ovarian Endometrioid Carcinoma and Ovarian Serous Carcinoma. J Pathol (2010) 220:392-400. doi: 10.1002/path.2659

93. Hollis RL, Stanley B, Iida Y, Thomson J, Churchman M, Rye T, et al. Hormone Receptor Expression Patterns Define Clinically Meaningful Subgroups of Endometrioid Ovarian Carcinoma. Gynecol Oncol (2019) 155:318-23. doi: 10.1016/j.ygyno.2019.09.001 
94. Kobel M, Rahimi K, Rambau PF, Naugler C, Le Page C, Meunier L, et al. An Immunohistochemical Algorithm for Ovarian Carcinoma Typing. Int $J$ Gynecol Pathol (2016) 35:430-41. doi: 10.1097/PGP.0000000000000274

95. Leskela S, Romero I, Rosa-Rosa JM, Caniego-Casas T, Cristobal E, PérezMies B, et al. Molecular Heterogeneity of Endometrioid Ovarian Carcinoma: An Analysis of 166 Cases Using the Endometrial Cancer Subrogate Molecular Classification. Am J Surg Pathol (2020) 44:982-90. doi: 10.1097/ PAS.0000000000001478

96. Kramer P, Talhouk A, Brett MA, Chiu DS, Cairns ES, Scheunhage DA, et al. Endometrial Cancer Molecular Risk Stratification is Equally Prognostic for Endometrioid Ovarian Carcinoma. Clin Cancer Res (2020) 26:5400-10. doi: 10.1158/1078-0432.CCR-20-1268

97. Kobel M, Luo L, Grevers X, Lee S, Brooks-Wilson A, Gilks CB, et al. Ovarian Carcinoma Histotype: Strengths and Limitations of Integrating Morphology With Immunohistochemical Predictions. Int J Gynecol Pathol (2019) 38:353-62. doi: 10.1097/PGP.0000000000000530

98. Fadare O, Parkash V. Pathology of Endometrioid and Clear Cell Carcinoma of the Ovary. Surg Pathol Clin (2019) 12:529-64. doi: 10.1016/ j.path.2019.01.009

99. Tothill RW, Tinker AV, George J, Brown R, Fox SB, Lade S, et al. Novel Molecular Subtypes of Serous and Endometrioid Ovarian Cancer Linked to Clinical Outcome. Clin Cancer Res (2008) 14:5198-208. doi: 10.1158/10780432.CCR-08-0196

100. MW G. Morphological Subtypes of Ovarian Carcinoma: A Review With Emphasis on New Developments and Pathogenesis. Pathology (2011) 43:420-32. doi: 10.1097/PAT.0b013e328348a6e7

101. Talhouk A, McConechy MK, Leung S, Li-Chang HH, Kwon JS, Melnyk N, et al. A Clinically Applicable Molecular-Based Classification for Endometrial Cancers. Br J Cancer (2015) 113:299-310. doi: 10.1038/bjc.2015.190

102. Lu KH, Broaddus RR. Endometrial Cancer. N Engl J Med (2020) 383:205364. doi: 10.1056/NEJMra1514010

103. Cybulska P, Paula ADC, Tseng J, Leitao MMJr., Bashashati A, Huntsman DG, et al. Molecular Profiling and Molecular Classification of Endometrioid Ovarian Carcinomas. Gynecol Oncol (2019) 154:516-23. doi: 10.1016/ j.ygyno.2019.07.012

104. Temko D, Van Gool IC, Rayner E, Glaire M, Makino S, Brown M, et al. Somatic POLE Exonuclease Domain Mutations are Early Events in Sporadic Endometrial and Colorectal Carcinogenesis, Determining Driver Mutational Landscape, Clonal Neoantigen Burden and Immune Response. J Pathol (2018) 245:283-96. doi: 10.1002/path.5081

105. McConechy MK, Talhouk A, Leung S, Chiu D, Yang W, Senz J, et al. Endometrial Carcinomas With POLE Exonuclease Domain Mutations Have a Favorable Prognosis. Clin Cancer Res (2016) 22:2865-73. doi: 10.1158/ 1078-0432.CCR-15-2233

106. Vierkoetter KR, Ayabe AR, VanDrunen M, Ahn HJ, Shimizu DM, Terada KY. Lynch Syndrome in Patients With Clear Cell and Endometrioid Cancers of the Ovary. Gynecol Oncol (2014) 135:81-4. doi: 10.1016/j.ygyno .2014 .07 .100

107. Shinmura H, Yoneyama K, Harigane E, Tsunoda Y, Fukami T, Matsushima $\mathrm{T}$, et al. Use of Tumor Markers to Distinguish Endometriosis-Related Ovarian Neoplasms From Ovarian Endometrioma. Int $J$ Gynecol Cancer (2020) 30:831-6. doi: 10.1136/ijgc-2020-001210

108. Matsuo K, Machida H, Frimer M, Marcus JZ, Pejovic T, Roman LD, et al. Prognosis of Women With Stage I Endometrioid Endometrial Cancer and Synchronous Stage I Endometrioid Ovarian Cancer. Gynecol Oncol (2017) 147:558-64. doi: 10.1016/j.ygyno.2017.09.027

109. Williams MG, Bandera EV, Demissie K, Rodríguez-Rodríguez L. Synchronous Primary Ovarian and Endometrial Cancers: A PopulationBased Assessment of Survival. Obstet Gynecol (2009) 113:783-9. doi: 10.1097/AOG.0b013e31819c7bdf

110. Mueller JJ, Pedra Nobre S, Braxton K, Alektiar KM, Leitao MMJr., Aghajanian C, et al. Incidence of Pelvic Lymph Node Metastasis Using Modern FIGO Staging and Sentinel Lymph Node Mapping With Ultrastaging in Surgically Staged Patients With Endometrioid and Serous Endometrial Carcinoma. Gynecol Oncol (2020) 157:619-23. doi: 10.1016/ j.ygyno.2020.03.025

111. Rambau P, Kelemen LE, Steed H, Quan ML, Ghatage P, Kobel M. Association of Hormone Receptor Expression With Survival in Ovarian
Endometrioid Carcinoma: Biological Validation and Clinical Implications. Int J Mol Sci (2017) 18:515. doi: 10.3390/ijms18030515

112. Sieh W, Köbel M, Longacre TA, Bowtell DD, deFazio A, Goodman MT, et al. Hormone-Receptor Expression and Ovarian Cancer Survival: An Ovarian Tumor Tissue Analysis Consortium Study. Lancet Oncol (2013) 14:853-62. doi: 10.1016/s1470-2045(13)70253-5

113. Chen S, Dai X, Gao Y, Shen F, Ding J, Chen Q. The Positivity of Estrogen Receptor and Progesterone Receptor may Not be Associated With Metastasis and Recurrence in Epithelial Ovarian Cancer. Sci Rep (2017) 7:16922. doi: 10.1038/s41598-017-17265-6

114. Cheng H, Wang Z, Cui L, Wen Y, Chen X, Gong F, et al. Opportunities and Challenges of the Human Microbiome in Ovarian Cancer. Front Oncol (2020) 10:163. doi: 10.3389/fonc.2020.00163

115. Cont NT, Ferrero A, Peccatori FA, D’Alonzo M, Codacci-Pisanelli G, Colombo N, et al. Medical Treatment of Early Stage and Rare Histological Variants of Epithelial Ovarian Cancer. Ecancermedicalscience (2015) 9:584. doi: 10.3332/ecancer.2015.584

116. National Comprehensive Cancer Network. (NCCN) Clinical Practice Guidelines in Oncology. Ovarian Cancer Including Fallopian Tube Cancer and Primary Peritoneal Cancer. (2020)

117. Chao A, Wu RC, Jung SM, Lee YS, Chen SJ, Lu YL, et al. Implication of Genomic Characterization in Synchronous Endometrial and Ovarian Cancers of Endometrioid Histology. Gynecol Oncol (2016) 143:60-7. doi: 10.1016/j.ygyno.2016.07.114

118. Anglesio MS, Wang YK, Maassen M, Horlings HM, Bashashati A, Senz J, et al. Synchronous Endometrial and Ovarian Carcinomas: Evidence of Clonality. J Natl Cancer Inst (2016) 108:djv428. doi: 10.1093/jnci/djv428

119. Colombo N, Creutzberg C, Amant F, Bosse T, González-Martín A, Ledermann J, et al. Esmo-Esgo-Estro Consensus Conference on Endometrial Cancer: Diagnosis, Treatment and Follow-Up. Ann Oncol (2016) 27:16-41. doi: 10.1016/j.radonc.2015.11.013

120. Rimar KJ, Tran PT, Matulewicz RS, Hussain M, Meeks JJ. The Emerging Role of Homologous Recombination Repair and PARP Inhibitors in Genitourinary Malignancies. Cancer (2017) 123:1912-24. doi: 10.1002/ cncr.30631

121. E P-L. New Treatments in Ovarian Cancer. Ann Oncol (2017) 28:viii57-60. doi: 10.1093/annonc/mdx442

122. Shen J, Peng Y, Wei L, Zhang W, Yang L, Lan L, et al. Aridla Deficiency Impairs the DNA Damage Checkpoint and Sensitizes Cells to PARP Inhibitors. Cancer Discovery (2015) 5:752-67. doi: 10.1158/2159-8290.CD14-0849

123. Ding L, Kim HJ, Wang Q, Kearns M, Jiang T. Parp Inhibition Elicits STINGDependent Antitumor Immunity in Brca1-Deficient Ovarian Cancer. Cell Rep (2018) 25:2972-29801. doi: 10.1016/j.celrep.2018.11.054

124. Shen J, Zhao W, Ju Z, Wang L, Peng Y, Labrie M, et al. Parpi Triggers the STING-Dependent Immune Response and Enhances the Therapeutic Efficacy of Immune Checkpoint Blockade Independent of Brcaness. Cancer Res (2019) 79:311-9. doi: 10.1158/0008-5472.CAN-18-1003

125. Lee EK, Konstantinopoulos PA. Combined PARP and Immune Checkpoint Inhibition in Ovarian Cancer. Trends Cancer (2019) 5:524-8. doi: 10.1016/ j.trecan.2019.06.004

126. Shi X, Wang J, Lei Y, Cong C, Tan D, Zhou X. Research Progress on the PI3K/AKT Signaling Pathway in Gynecological Cancer (Review). Mol Med Rep (2019) 19:4529-35. doi: 10.3892/mmr.2019.10121

127. Xiao X, Dong D, He W, Song L, Wang Q, Yue J, et al. Mismatch Repair Deficiency is Associated With MSI Phenotype, Increased TumorInfiltrating Lymphocytes and PD-L1 Expression in Immune Cells in Ovarian Cancer. Gynecol Oncol (2018) 149:146-54. doi: 10.1016/j.ygyno .2018.02.009

128. Dai S, Jia R, Zhang X, Fang Q, Huang L. The PD-1/PD-Ls Pathway and Autoimmune Diseases. Cell Immunol (2014) 290:72-9. doi: 10.1016/ j.cellimm.2014.05.006

129. Yao J, Gong Y, Zhao W, Han Z, Guo S, Liu H, et al. Comprehensive Analysis of POLE and POLD1 Gene Variations Identifies Cancer Patients Potentially Benefit From Immunotherapy in Chinese Population. Sci Rep (2019) 9:15767. doi: 10.1038/s41598-019-52414-Z

130. Dong ZY, Zhong WZ, Zhang XC, Su J, Xie Z, Liu SY, et al. Potential Predictive Value of TP53 and KRAS Mutation Status for Response to PD-1 
Blockade Immunotherapy in Lung Adenocarcinoma. Clin Cancer Res (2017) 23:3012-24. doi: 10.1016/j.jtho.2016.11.504

131. Li J, Pan C, Boese AC, Kang J, Umano AD, Magliocca KR, et al. Dgka Provides Platinum Resistance in Ovarian Cancer Through Activation of cJUN-WEE1 Signaling. Clin Cancer Res (2020) 26:3843-55. doi: 10.1158/ 1078-0432.CCR-19-3790

132. Fang Y, McGrail DJ, Sun C, Labrie M, Chen X, Zhang D, et al. Sequential Therapy With PARP and WEE1 Inhibitors Minimizes Toxicity While Maintaining Efficacy. Cancer Cell (2019) 35:851-67. doi: 10.1016/ j.ccell.2019.05.001

133. Leijen S, van Geel RM, Sonke GS, de Jong D, Rosenberg EH, Marchetti S, et al. Phase II Study of WEE1 Inhibitor AZD1775 Plus Carboplatin in Patients With TP53-Mutated Ovarian Cancer Refractory or Resistant to First-Line Therapy Within 3 Months. J Clin Oncol (2016) 34:4354-61. doi: 10.1200/JCO.2016.67.5942

134. Pawłowska A, Suszczyk D, Okła K, Barczyński B, Kotarski J, Wertel I. Immunotherapies Based on PD-1/PD-L1 Pathway Inhibitors in Ovarian Cancer Treatment. Clin Exp Immunol (2019) 195:334-44. doi: 10.1111/cei.13255

135. Pietzner K, Nasser S, Alavi S, Darb-Esfahani S, Passler M, Muallem MZ, et al. Checkpoint-Inhibition in Ovarian Cancer: Rising Star or Just a Dream? J Gynecol Oncol (2018) 29:e93. doi: 10.3802/jgo.2018.29.e93

136. Zerdes I, Matikas A, Bergh J, Rassidakis GZ, Foukakis T. Genetic, Transcriptional and Post-Translational Regulation of the Programmed Death Protein Ligand 1 in Cancer: Biology and Clinical Correlations. Oncogene (2018) 37:4639-61. doi: 10.1038/s41388-018-0303-3

137. Zhu X, Lang J. Programmed Death-1 Pathway Blockade Produces a Synergistic Antitumor Effect: Combined Application in Ovarian Cancer. J Gynecol Oncol (2017) 28:e64. doi: 10.3802/jgo.2017.28.e64

138. Pan Y, Kao MS. Endometrioid Ovarian Carcinoma Benefits From Aromatase Inhibitors: Case Report and Literature Review. Curr Oncol (2010) 17:82-5. doi: $10.3747 /$ co.v17i6.676

139. Langdon SP, Herrington CS, Hollis RL, Gourley C. Estrogen Signaling and Its Potential as a Target for Therapy in Ovarian Cancer. Cancers (2020) 12:11647. doi: 10.3390/cancers 12061647

140. George A, McLachlan J, Tunariu N, Della Pepa C, Migali C, Gore M, et al. The Role of Hormonal Therapy in Patients With Relapsed High-Grade Ovarian Carcinoma: A Retrospective Series of Tamoxifen and Letrozole. BMC Cancer (2017) 17:456. doi: 10.1186/s12885-017-3440-0

141. B A, G H, L SP, L A, S M, Y A, et al. CA125 Response is Associated With Estrogen Receptor Expression in a Phase II Trial of Letrozole in Ovarian Cancer: Identification of an Endocrine-Sensitive Subgroup. Clin Cancer Res (2002) 8:2233-9.

142. Pedernera E, Gomora MJ, Morales-Vasquez F, Perez-Montiel D, Mendez C. Progesterone Reduces Cell Survival in Primary Cultures of Endometrioid Ovarian Cancer. J Ovarian Res (2019) 12:15. doi: 10.1186/s13048-019-0486-4

143. Helmink BA, Khan MAW, Hermann A, Gopalakrishnan V, Wargo JA. The Microbiome, Cancer, and Cancer Therapy. Nat Med (2019) 25:377-88. doi: 10.1038/s41591-019-0377-7
144. Routy B, Le Chatelier E, Derosa L, Duong C, Alou MT, Daillère R, et al. Gut Microbiome Influences Efficacy of PD-1-based Immunotherapy Against Epithelial Tumors. Science (2018) 359:91-7. doi: 10.1126/science.aan3706

145. Zhao Y, Wang S, Qu YM, Ji YT, Shen K, Lang JH. Prognostic Analysis for Chinese Patients With Stage I Ovarian Endometrioid Carcinoma. J Ovarian Res (2017) 10:63. doi: 10.1186/s13048-017-0361-0

146. Leskela S, Romero I, Cristobal E, Pérez-Mies B, Rosa-Rosa JM, GutierrezPecharroman A, et al. The Frequency and Prognostic Significance of the Histologic Type in Early-stage Ovarian Carcinoma: A Reclassification Study by the Spanish Group for Ovarian Cancer Research (Geico). Am J Surg Pathol (2020) 44:149-61. doi: 10.1097/PAS.0000000000001365

147. Soyama H, Miyamoto M, Takano M, Iwahashi H, Kato K, Sakamoto T, et al. A Pathological Study Using 2014 WHO Criteria Reveals Poor Prognosis of Grade 3 Ovarian Endometrioid Carcinomas. In Vivo (2018) 32:597-602. doi: 10.21873/invivo.11281

148. Yoneoka Y, Yoshida H, Ishikawa M, Shimizu H, Uehara T, Murakami T, et al. Prognostic Factors of Synchronous Endometrial and Ovarian Endometrioid Carcinoma. J Gynecol Oncol (2019) 30:e7. doi: 10.3802/ jgo.2019.30.e7

149. Wang L, Rambau PF, Kelemen LE, Anglesio MS, Leung S, Talhouk A, et al. Nuclear Beta-Catenin and CDX2 Expression in Ovarian Endometrioid Carcinoma Identify Patients With Favourable Outcome. Histopathology (2019) 74:452-62. doi: 10.1111/his.13772

150. Le Page C, Kobel M, Meunier L, Provencher DM, Mes-Masson AM, Rahimi K. A COEUR Cohort Study of SATB2 Expression and its Prognostic Value in Ovarian Endometrioid Carcinoma. J Pathol Clin Res (2019) 5:177-88. doi: $10.1002 / c j p 2.131$

151. Rambau PF, Vierkant RA, Intermaggio MP, Kelemen LE, Goodman MT, Herpel E, et al. Association of p16 Expression With Prognosis Varies Across Ovarian Carcinoma Histotypes: An Ovarian Tumor Tissue Analysis Consortium Study. J Pathol Clin Res (2018) 4:250-61. doi: $10.1002 / \mathrm{cjp} 2.109$

152. Engqvist H, Parris TZ, Kovacs A, Ronnerman EW, Sundfeldt K, Karlsson P, et al. Validation of Novel Prognostic Biomarkers for Early-Stage Clear-Cell, Endometrioid and Mucinous Ovarian Carcinomas Using Immunohistochemistry. Front Oncol (2020) 10:162. doi: 10.3389/ fonc. 2020.00162

Conflict of Interest: The authors declare that the research was conducted in the absence of any commercial or financial relationships that could be construed as a potential conflict of interest.

Copyright (๑) 2021 Chen, Li, Qian, Deng, Liu, Xiao and Zhou. This is an open-access article distributed under the terms of the Creative Commons Attribution License (CC BY). The use, distribution or reproduction in other forums is permitted, provided the original author(s) and the copyright owner(s) are credited and that the original publication in this journal is cited, in accordance with accepted academic practice. No use, distribution or reproduction is permitted which does not comply with these terms. 